\title{
Periapical Cyst Repair After Nonsurgical Endodontic Therapy - Case Report
}

\author{
Caroline R.A. VALOIS \\ Edson Dias COSTA-JÚNIOR
}

Faculty of Health Sciences, Department of Dentistry, University of Brasília (UnB), Brasília, DF, Brazil

\begin{abstract}
This article presents the procedures that must be considered for periapical cyst repair after nonsurgical endodontic treatment. The case of a periapical cyst associated to the left maxillary lateral incisor is reported. Nonsurgical root canal therapy was performed and lesion healing was confirmed radiographically after 24 months. Differential diagnosis, endodontic infection control, apical foramen enlargement and filling of the cystic cavity with a calcium hydroxide paste were important procedures for case resolution.
\end{abstract}

Key Words: endodontic therapy, periapical cyst, periapical pathosis.

\section{INTRODUCTION}

The periapical cyst is originated from the epithelium in a granuloma and is frequently associated to an inflammatory response of the organism against a long-term local aggression due to an endodontic infection. This condition is clinically asymptomatic but can result in a slow-growth tumefaction in the affected region. Radiographically, the classic description of the lesion is a round or oval, well-circumscribed radiolucent image involving the apex of the infected tooth (1).

Although it has been demonstrated that this pathologic entity can represent 40 to $50 \%$ of all apical lesions (2), it is not yet well-established in the literature whether its treatment should be surgical or non-surgical. Some authors support that if the endodontic infection is eliminated, the immune system is able to promote lesion repair, while other believe that surgical intervention is invariably necessary (1-5).

In this article, a case of periapical cyst healing after nonsurgical endodontic treatment is reported.

\section{CASE REPORT}

A 42 year-old female patient was referred to our clinic for endodontic treatment of the left maxillary lateral incisor. Intraoral clinical examination revealed that the lateral incisor had esthetic restorations on the mesial, distal and lingual surfaces. The buccal mucosa presented normal color and appearance. There was no gingival or extraoral swelling but a volumetric increase in the palate was observed. The patient denied spontaneous pain but reported painful symptomatolgy upon percussion.

The radiographic examination showed the presence of external periapical resorption of approximately $1 \mathrm{~mm}$ length and a radiolucent lesion (15 $\mathrm{x} 10 \mathrm{~mm}$ ) surrounded by a tenuous radiopaque line adjacent to the apex of tooth 22. Pulpal necrosis was confirmed by cold sensitivity testing done with EndoFrost cold spray (Roeko, Langenau, Germany).

After crown opening, a mucous and transparent exudate drained through the radicular canal. A sample of this fluid was collected for cytological examination. The canal was instrumented at $1 \mathrm{~mm}$ from the apical foramen according to the crown-down technique. The memory instrument was a size $60 \mathrm{~K}$-file (Maillefer Instruments SA, Ballaigues, Switzerland). The canal was irrigated with HCT20, an irrigating solution composed of calcium hydroxide, tergentol and distilled water (6), and filled with a paste prepared with 9 parts of calcium hydroxide and 1 part of zinc oxide in an

Correspondence: Dr. Edson D. Costa Jr., Faculdade de Odontologia, Universidade de Brasília (UnB), Campus Universitário, Asa Norte, 70910-900 Brasília, DF, Brasil. Tel: +55-61-307-2632. e-mail: cravalois@uol.com.br/edsondias@opendf.com.br 
aqueous vehicle (HCT20), using a lentulo drill. Canal entrance was sealed with a non-eugenol, pre-mixed temporary filling material (Cimpat, Septodont, Saint Maur, France) and the access cavity was closed with a rapid-setting zinc oxide and eugenol based cement (Pulpo-san, SS White, Rio de Janeiro, RJ, Brazil). All procedures were carried out under absolute isolation.

The exfoliating cytology of the lesion's fluid was compatible with periapical cyst. The patient returned for a second visit and was informed about the diagnosis, tooth conditions and treatment options. She agreed to sign an informed consent form for nonsurgical root canal therapy and documentation of her case.

The provisional restoration was removed and the canal was irrigated with HCT20 and filled with intracanal medication. A size 30 K-file (Maillefer Instruments SA) was introduced $3 \mathrm{~mm}$ beyond the radiographic apex (Fig. 1). At this moment, an abundant serum, purulent and hemorrhagic exudate flowed through the root canal. The calcium hydroxide paste was reapplied into the canal and intentionally taken to the periapical region using a size $30 \mathrm{~K}$-file as described above. All procedures were carried out under absolute isolation.

During the first month, the patient returned every week for control and, after that, monthly appointments were scheduled. The intracanal medication was renewed at each visit. One month after the beginning of the treatment, the radiographic examination showed that practically all calcium hydroxide paste extruded into the periapical lesion had been resorbed. Therefore, placement of intracanal dressing beyond the tooth apex was repeated, but this time greater paste volume was used to completely fill the cystic cavity (Fig. 2).

During the following three months of treatment, renewal of intracanal medication was associated to increase of sensitivity to percussion and palate tumefaction. A fistula developed and persisted during four days. At the fifth month of follow-up, it was observed absence of sensitivity to percussion, fistula, tumefaction and exudate drainage through the canal. Therefore, at the subsequent visits, there was no longer need to take the intracanal medication to the cystic cavity by advancing the file $3 \mathrm{~mm}$ beyond the apical foramen. After fourteen months of treatment, periapical radiographs showed a remarkable decrease of the radiolucency of the lesion and partial resorption of the calcium hydroxide paste (Fig. 3).

The root canal was chemomechanically prepared, obturated with gutta-percha cones (Dentsply Ind. Com. Ltda, Petrópolis, RJ, Brazil) and Sealer 26 cement (Dentsply Ind. Com. Ltda) using the lateral condensation technique. A definitive restoration was then placed.

The patient returned for clinical and radiographic controls every 6 months during the first 2 years, and then every 12 months during the following 3 years (Fig. 4). Radiographic evidence of lesion healing was observed at the 24-month follow-up.

\section{DISCUSSION}

It is known that a pulpal infection originates and perpetuates periapical pathologic alterations. In addition, in the absence of aggressive agents, the immune system has mechanisms to promote the repair of tissues and structures affected by pathologic processes (3). Therefore, the elimination of harmful agents from the root canal system creates a propitious environment for repair of a cystic lesion $(3,5)$.

Parendodontic surgeries may have direct procedural consequences that make nonsurgical endodontic treatment preferable over them in cases of periapical cyst. Among the events that might be associated to periapical surgical interventions are loss of bone support, possibility of damaging blood vessels and nerves irrigating and innervating teeth adjacent to the lesion, possibility of damaging anatomic structures, such as the mental foramen, inferior alveolar nerve and/ or artery, nasal cavity and the maxillary sinus, production of anatomic defects or scars, postoperative pain or discomfort, and refusal to undergo surgical procedures, especially pediatric patients $(4,5)$.

Studies have reported that periapical cysts are refractory to non-surgical endodontic therapy $(7,8)$. Nevertheless, the fact that these findings are associated to other etiological factors, such as extraradicular infection, presence of foreign bodies and cholesterol crystals, has also been discussed in the literature (8). Furthermore, the way that the endodontic treatment is conducted should be discussed as well. Correct planning of the intervention in cases of periapical cyst is of paramount importance for a successful therapy.

The foremost step is to establish a differential diagnosis between periapical cyst and periapical granuloma. Several studies have shown the difficulty to distinguish radiographically these pathological entities $(9,10)$. Biochemical procedures have also been described 


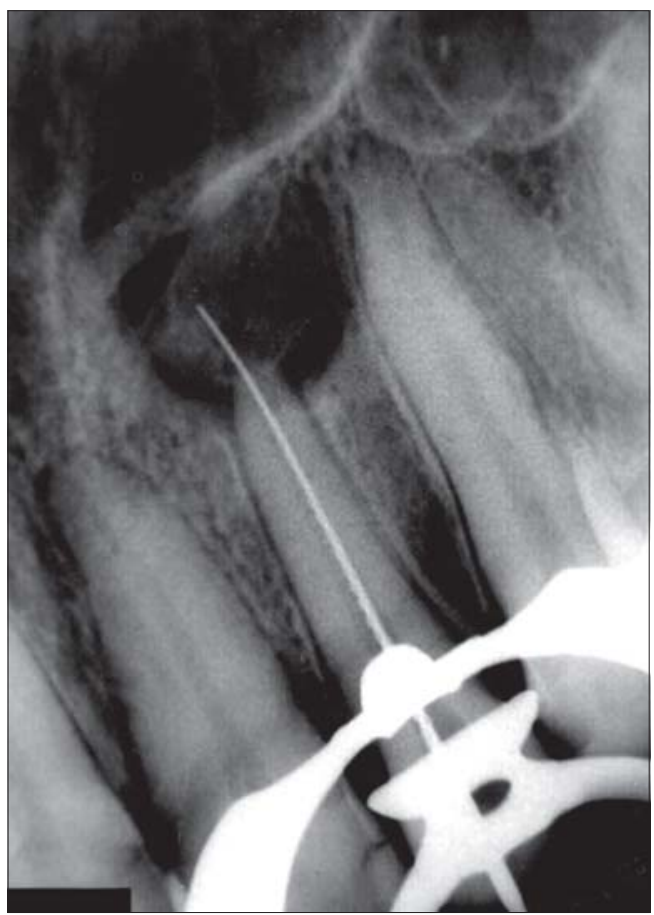

Figure 1. Radiograph showing a periradicular cyst associated to the left maxillary lateral incisor. Note the intentional placement of an endodontic file beyond the apex into the cystic cavity.

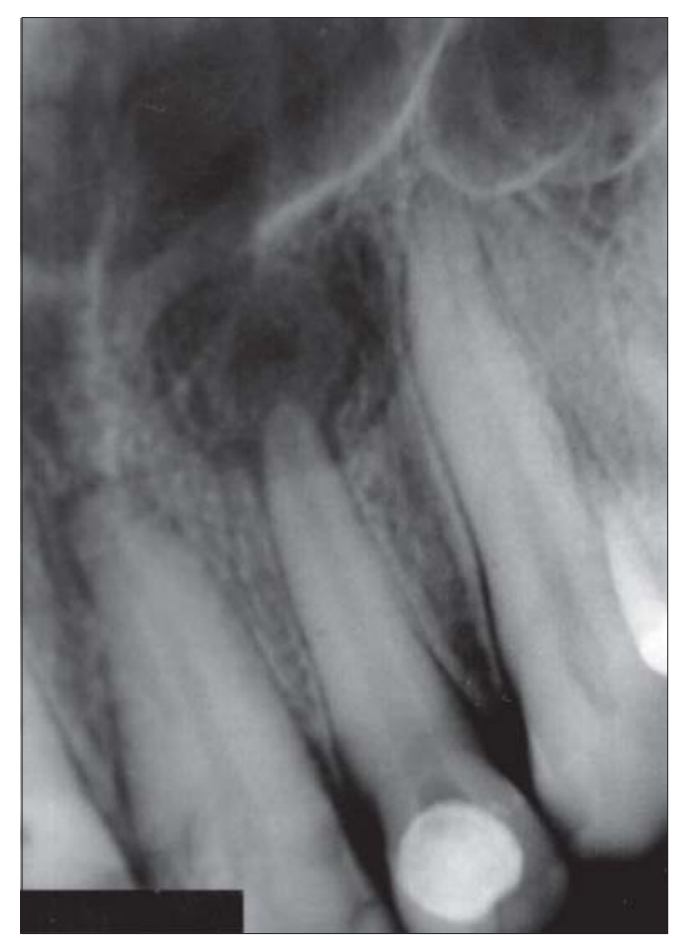

Figure 3. Radiograph taken 14 months after the beginning of the nonsurgical endodontic therapy. Note a remarkable decrease of the lesion radiolucency with partial resorption of the paste.

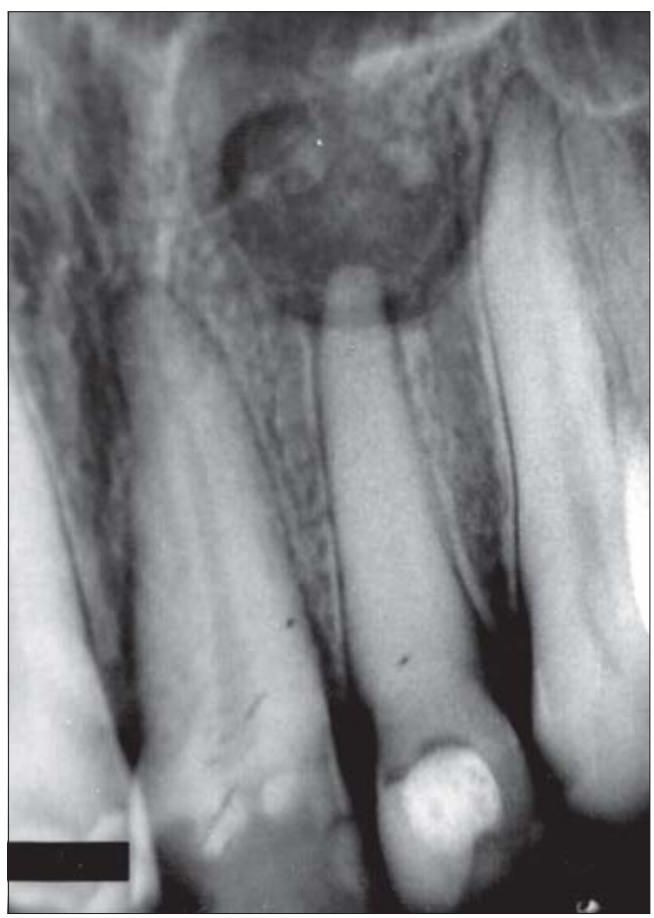

Figure 2. Radiograph taken 1 month after the beginning of the nonsurgical root canal therapy. Note the cystic cavity completely filled with the calcium hydroxide-based intracanal medication.

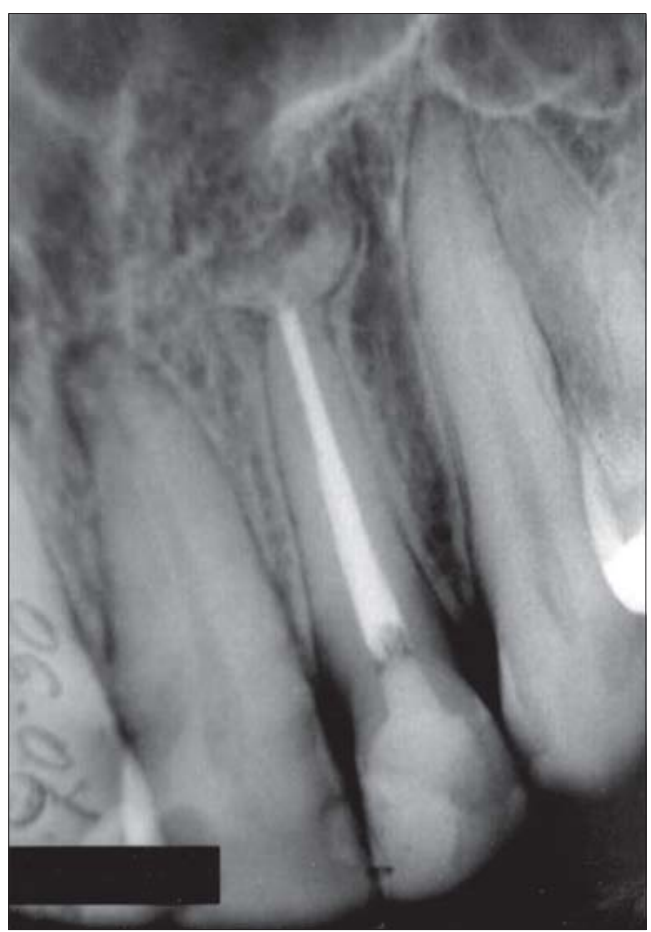

Figure. Radiograph taken 5 years after completion of the nonsurgical endodontic therapy. Note complete healing of the periradicular cyst and resorption of the paste. 
for differencial diagnosis $(4,11)$. In the case reported in this article, exfoliating cytology was the chosen method to examine the lesion's fluid because it has a simplified technique.

Endodontic infection control is another crucial point to be addressed while planning the intervention. For elimination or maximum reduction of microorganisms in the root canal system, the professional should associate debridment using endodontic files with efficient irrigating solution and intracanal medication. Moreover, patency and elargement of the canals in case of necrotic teeth with periapical lesions will help eliminating microorganisms from the apical foramen, thus preventing the inflammatory process to perpetuate. Calcium hydroxide irrigants and dressings were selected because they reportedly provide excellent clinical and laboratorial results $(6,12,14,15)$. Calcium hydroxide was associated to an aqueous vehicle to allow rapid release of $\mathrm{Ca}^{++}$and $\mathrm{OH}$. Zinc oxide was added to the paste to allow better visualization of the medication within the canal and the cystic cavity.

Overextension of calcium hydroxide paste into cystic lesions, as performed in the case reported, has been previously described $(12,13,16)$. The benefits of this procedure include anti-inflammatory action through hygroscopic properties forming calcium proteinate bridges and inhibiting phospholipase, neutralization of acidic products such as hidrolases, which can affect the clastic activity, activation of the alkaline phosphatase, antibacterial effect and the destruction of the cystic epithelium, allowing conjunctive tissue invagination to the lesion $(12,13)$.

Bhaskar (2) suggested that, during the endodontic therapy of teeth associated with periapical cysts, root canal instrumentation must be done slightly beyond the apical foramen. According to the author, this will produce a transitory acute inflammation and destruction of the protective epithelial layer of the cyst, converting it into a granulated tissue, which has better resolution. Although there is no scientific-based evidence that support this assumption, in the case hereby presented, instrumentation beyond the apical foramen was carried out because it would help eliminating microorganisms from the apical area, thus reducing the inflammatory process. Moreover, it could also facilitate cyst resolution through the relief of the intra-cystic pressure (1).

The criteria used to establish the most adequate moment for obturation of the root canal are associated with absence of spontaneous pain, sensitivity to percussion, exudate and edema, and the beginning of radiographic regression of the lesion. Regarding the time required for considering the therapy successful, a two-year period has been considered a reasonable interval (17). In the case described in this paper, the patient was evaluated biannually and then every 12 months up to 5 years of follow-up.

Differential diagnosis, endodontic infection control, apical foramen enlargement and filling of the cystic cavity with a calcium hydroxide paste were proved important procedures for successful nonsurgical endodontic treatment of periapical cysts.

\section{RESUMO}

O objetivo do presente estudo foi apresentar os procedimentos a serem considerados para o tratamento endodôntico não-cirúrgico de cistos periapicais. Um caso de cisto periapical associado ao incisivo lateral superior esquerdo é relatado. Após o tratamento endodôntico não-cirúrgico, o reparo da lesão foi observado radiograficamente em 24 meses. Diagnóstico diferencial, controle da infecção endodôntica, alargamento do forame apical e preenchimento da cavidade cística com pasta de hidróxido de cálcio foram procedimentos relevantes para a resolução do caso.

\section{REFERENCES}

1. Shear M. Cistos da região bucomaxilofacial. 3th ed. São Paulo: Editora Santos; 1999.

2. Bhaskar SN. Nonsurgical resolution of radicular cysts. Oral Surg 1972;34:458-468.

3. Maalouf EM, Gutmann JL. Biological perspectives on the non-surgical endodontic management of perirradicular pathosis. Int Endod J 1994;27:154-162.

4. Morse DR, Bhambhani SM. A dentist's dilemma: nonsurgical endodontic therapy or periapical surgery for teeth with apparent pulpal pathosis and an associated periapical radiolucent lesion. Oral Surg Oral Med Oral Pathol Oral Radiol Endod 1990;70:333-340.

5. Shah N. Nonsurgical management of periapical lesions: a prospective study. Oral Surg Oral Med Oral Pathol Oral Radiol Endod 1988;66:365-371.

6. Barbosa SV, Spangberg LS, Almeida D. Low surface tension calcium hydroxide solution is an effective antiseptic. Int Endod J 1994;27:6-10.

7. Nobuhara WK, Del Rio CE. Incidence of perirradicular pathoses in endodontic treatment failures. J Endod 1993;19:315-318.

8. Nair PNR, Sjögren U, Figdor D, Sundqvist G. Persistent periapical radiolucencies of root-filled human teeth, failed endodontic treatments and periapical scars. Oral Surg Oral Med Oral Pathol Oral Radiol Endod 1999;87:617-627.

9. Mortensen H, Winther JE, Birn H. Periapical granulomas and cysts. An investigation of 1.600 cases. Scand J Dent Res 1970;78:241-250. 
10. Kizil Z, Energin K. An evaluation of radiographic and histopathological findings in periapical lesions. J Marmara Univ Dent Fac 1990;1:16-23.

11. Morse DR, Patnik JW, Schacterle GR. Electrophoretic differentiation of radicular cysts and granulomas. Oral Surg Oral Med Oral Pathol Oral Radiol Endod 1973;35:249-264.

12. Sahli CC. L'hydroxide de calcium dans le traitment endodontique des grandes lesions periapicales. Rev Fran D’Endodoncia 1998;7:45-51.

13. Souza V, Bernabe PFE, Holland R, Nery MJ, Mello W, Otoboni Filho JA. Tratamento não cirúrgico de dentes com lesões perirradiculares. Rev Bras Odont 1989;46:39-46.
14. Çaliskan MK, Sem BH. Endodontic treatment of teeth with apical periodontitis using calcium hydroxide: a long-term study. Endod Dent Traumatol 1996;12:215-221.

15. Siqueira Jr. JF, Lopes HP. Mechanisms of antimicrobial activity of calcium hydroxide: a critical review. Int Endod J 1999;32:361-369.

16. Çaliskan MK, Türkün M. Periapical repair and apical closure of a pulpless tooth using calcium hydroxide. Oral Surg Oral Med Oral Pathol Oral Radiol Endod 1997;84:683-687.

17. Bender IB, Seltzer S, Soltanoff W. Endodontic success - a reappraisal of criteria. Oral Surg Oral Med Oral Pathol Oral Radiol Endod 1966;22:780-802.

Accepted June 27, 2004 